\title{
Cryptosporidiosis caused by Cryptosporidium parvum subtype IIdA15G1 at a dairy farm in Northwestern China
}

\author{
Zhaohui Cui ${ }^{1,2}$, Rongjun Wang ${ }^{1,2^{*}}$, Jianying Huang ${ }^{1,2}$, Haiyan Wang ${ }^{1,2}$, Jinfeng Zhao ${ }^{1,2}$, Nannan Luo ${ }^{1,2}$, Jungiang Li ${ }^{1,2}$,
} Zhenjie Zhang ${ }^{1,2}$ and Longxian Zhang ${ }^{1,2^{*}}$

\begin{abstract}
Background: Cryptosporidium spp. are zoonotic parasites responsible for diarrhoeal diseases in animals and humans worldwide. Cattle are the most common mammalian species in which Cryptosporidium is detected, with pre-weaned calves considered to be reservoirs for zoonotic C. parvum. In October 2013, severe diarrhoea was observed in 396 pre-weaned calves at a farm in the Ningxia Autonomous Region of Northwestern China. 356 of the infected calves died despite antibiotic therapy.

Findings: 252 faecal samples were collected from the investigated farm. The identity of Cryptosporidium species was determined by polymerase chain reaction (PCR) restriction fragment length polymorphism (RFLP) analysis, and by DNA sequence analysis of the small subunit (SSU) rRNA gene. C. parvum was subtyped using sequence analysis of the $60 \mathrm{kDa}$ glycoprotein (gp60) gene. The highest infection rate of 83.3\% (40/48) was seen in 2-3-week-old calves with diarrhoea, corresponding to the age at which animals died. Three Cryptosporidium species were identified, including C. parvum $(n=51)$, C. bovis $(n=1)$, and C. ryanae $(n=1)$. All C. parvum isolates were further identified as subtype IIdA15G1.

Conclusions: Cryptosporidium parvum was likely to be most responsible for diarrhoea and death. This is the first report of a cryptosporidiosis outbreak caused by C. parvum IIdA15G1 in Chinese dairy cattle.
\end{abstract}

Keywords: Cryptosporidium parvum, Outbreak, Dairy cattle, SSU rRNA, gp60

\section{Background}

Species of Cryptosporidium are important zoonotic parasites that infect a wide range of vertebrate hosts, including humans [1]. There are extensive genetic variations within the Cryptosporidium genus. In addition to 27 recognized species of Cryptosporidium, more than 70 Cryptosporidium genotypes with no designated species names have been described [2-5]. Cryptosporidium can be transmitted by the faecal-oral route, via either direct contact or ingestion of contaminated food or water [1].

Cryptosporidiosis, caused by Cryptosporidium infection, is of great concern because of associated economic losses and the public health significance in humans. Diarrhoea is

\footnotetext{
*Correspondence: wrj-1978@163.com; zhanglx8999@gmail.com

${ }^{1}$ College of Animal Science and Veterinary Medicine, Henan Agricultural University, Zhengzhou 450002, China

${ }^{2}$ International Joint Research Laboratory for Zoonotic Diseases of Henan, Zhengzhou 450002, China
}

a typical clinical sign of human and animal cryptosporidiosis; dehydration, fever, nausea and anorexia are sometimes symptoms in infected hosts. Over 200 water-borne, food-borne, person-to-person, and zoonotic cryptosporidiosis outbreaks have been recorded [6]. The most famous cryptosporidiosis outbreak occurred in Milwaukee (Wisconsin, USA), where 403,000 people were infected through contaminated drinking water [7]. In recent years, cryptosporidiosis outbreaks have been reported in several European and American countries [8-11]. Molecular techniques have shown that $C$. parvum is the predominant species in cryptosporidiosis outbreaks, accounting for $50.8 \%$ of cases among 325 water-borne outbreaks of parasitic protozoan diseases worldwide [6].

Cattle are the most common mammalian species in which Cryptosporidium is detected; pre-weaned calves are considered reservoirs for zoonotic C. parvum [12]. 
Of 14 C. parvum subtype families (IIa, IIb, IIc, IId, IIe, IIf, IIg, IIh, IIi, IIk, IIl, IIm, IIn, and IIo), IIa and IId are the two major zoonotic subtype families in animals and humans, while IIc and IIe are anthroponotic subtype families [13]. Other subtype families of C. parvum are occasionally seen in humans and other animals $[2,14]$.

In China, Cryptosporidium infections have been reported in domestic animals, wild animals, and humans [13-18]. A cryptosporidiosis outbreak was noticed in a paediatric hospital in Shanghai [19]. In the current study we have briefly described a cryptosporidiosis outbreak that occurred at a dairy farm in the Ningxia Autonomous Region (Northwestern China). The infection rate and species distribution of Cryptosporidium were also determined.

\section{Materials}

\section{Cryptosporidiosis outbreak}

The investigated farm, located in the Ningxia Autonomous Region of Northwestern China, was established in July 2012 with 7000 dairy cattle (2600 calves and 4400 adult cattle). The breeding cattle were introduced from Australia and Uruguay, while forage was produced in the United States. Previously, vaccination was not done against rotaviruses, coronaviruses, and $E$. coli. Before this outbreak, Cryptosporidium oocysts were not detected using conventional faecal examination by microscopy. In October 2013, severe diarrhoea was observed in 396 preweaned calves on this farm. 356 of the calves, in particular the 2-3-week-olds, died despite being treated with antibiotics. We collected 30 faecal samples from calves with diarrhoea and subjected them to testing for gastrointestinal pathogens [Rota, Corona, E. coli F5 (K99), Crypto] using the commercial Digestive Kit (Real Bio-technology, Qingdao, China). One month later, the symptom of diarrhoea gradually disappeared in calves.

\section{Ethics statement}

During specimen collection, all animal experiments were conducted in accordance with the Chinese Laboratory Animal Administration Act 1988.Prior to experiment, the protocol of the current study wasreviewed and approved by the Research Ethics Committee of Henan Agricultural University (License no. 2014-018).

\section{Sampling and microscopy examination}

To determine infection rate and species distribution of Cryptosporidium, we obtained 252 faecal samples: 158 were from pre-weaned calves, 55 from post-weaned calves, and 39 from heifers and adults. Fresh faecal samples for each animal were collected immediately after defecation on the ground. Cryptosporidium oocysts in faecal samples were concentrated using Sheather's sugar flotation technique, with samples from pre-weaned calves subjected to formalin-ethyl acetate sedimentation [14].
Cryptosporidium-positive samples were determined by microscopy and stored in $2.5 \%$ potassium dichromate at $4^{\circ} \mathrm{C}$ prior to DNA extraction.

\section{Molecular identification}

Genomic DNA was extracted from Cryptosporidiumpositive faecal samples using the E.Z.N.A. Stool DNA kit (Omega Biotek Inc., Norcross, GA, USA) according to the manufacturer's recommended procedures. Cryptosporidium species were determined by polymerase chain reaction (PCR) restriction fragment length polymorphism (RFLP) analysis, and by DNA sequence analysis of the small subunit (SSU) rRNA gene [20]. Subtyping of C. parvum was conducted using a nested PCR technique targeting the gp60 gene, which encodes the $60 \mathrm{kDa}$ glycoprotein $[2,21]$. Amplicons were sequenced on an ABI PRISMTM 3730 XL DNA Analyzer using the Big Dye Terminator v3.1 Cycle Sequencing Kit (Applied Biosystems, Foster City, CA, USA). Sequence accuracy was confirmed by twodirectional sequencing and by sequencing a fresh PCR amplicon if necessary. Sequence alignment was carried out using ClustalX 1.83 (ftp://ftp-igbmc.u-strasbg.fr/pub/ ClustalX/). Representative nucleotide sequences were deposited in GenBank (Accession numbers KM215133KM215134, and KM873712-KM873713).

\section{Findings and discussion}

Using the Digestive Kit, we found that nine samples were positive for Cryptosporidium and four were positive for rotavirus. None of the samples analyzed with the Digestive Kit were positive for coronavirus or E. coli F5 (K99).

Microscopy examination revealed the overall prevalence of Cryptosporidium to be $21 \%$ (53/252). The infection rate was 31 (49/158), $7.3(4 / 55)$, and $0 \%$ (0/39) for pre-weaned, 3-11-month-old, and >1-year-old animals, respectively. The highest infection rate of $83.3 \%(40 / 48)$ was seen in 2-3-week-old calves that had severe diarrhoea. Three Cryptosporidium species were identified based on RFLP and sequence analysis of the SSU rRNA gene; there were 51 C. parvum isolates in pre-weaned $(n=48)$ and 3 -11-month-old $(n=3)$ calves, one $C$. bovis isolate in a 3-11-month-old calf, and one C. ryanae isolate in a preweaned calf. All C. parvum isolates were successfully amplified at the gp60 locus, with sequencing analysis suggesting they were the IIdA15G1 subtype.

Diarrhoea is common in calves worldwide, and is considered a major cause of productivity decline and economic losses in the cattle industry [22]. Previous studies have indicated that rotaviruses, coronaviruses, E. coli, and C. parvum are all contributing factors to diarrhoea in calves. However, C. parvum is believed to be the primary cause of calf diarrhoea, and is a potential zoonotic agent $[23,24]$. Results from the Digestive Kit in combination with high Cryptosporidium prevalence (83.3\%) in 
2-3-week-old calves with diarrhoea were strong indicators that $C$. parvum was likely most responsible for diarrhoea and death.

An overall infection rate of $21 \%$ on this farm was higher than that observed in Heilongjiang (15.0\%), Henan (13.0\%), and Shannxi (3.4\%) provinces in China [14,25-28]. The highest level of prevalence (83.3\%) in 2-3-week-old calves was similar to that seen in previous studies [29], and was consistent with the morbidity and mortality of calves in this age group.

The predominance of $C$. parvum infection in preweaned calves seen in this study was highly similar to those seen in most studies conducted in other countries $[2,14,27,28]$. It is known that C. parvum is a major etiological agent for sporadic cases, or water- and food-borne disease outbreaks in humans worldwide [9,30-33]. As a major reservoir of $C$. parvum, pre-weaned calves might play an important role in zoonotic infections [12].

Previously, the $C$. parvum subtype IIdA15G1 has been detected in cattle, sheep and goats in Iran, Malaysia, and Spain [34-37]. It has also been found in humans from the Netherlands, Australia, Iran, Malaysia, and India [37-41]. The IIdA15G1 subtype identified in this study was unlikely to have arrived via Uruguay or the United States because the C. parvum IId subtype family has never been found in the Americas [13]. It is also unlikely that IIdA15G1 was introduced from Australia because C. parvum has not been detected in Australian breeding cattle. Thus, the source of the cryptosporidiosis outbreak could be attributed to $C$. parvum contamination in the area surrounding the farm. The IIdA15G1 subtype has been found in rodents in China, with C. parvum isolates from animals all belonging to the IId subtype $[14,18,27,28]$. Generally, IId is a major zoonotic subtype family reported in Europe (Hungary, Germany, Portugal, Sweden, Ireland, Spain, Belgium, Romania, the United Kingdom, the Netherlands, Slovenia, and Serbia and Montenegro), Asia (Kuwait, Iran, Jordan, India, Malaysia, and China), Africa (Egypt and Ethiopia), and Australia $[13,14,42,43]$.

In comparison with cryptosporidiosis outbreaks in humans, only a few outbreaks have been reported in animals, including goats in Brazil and Oman [44,45], foals in New Zealand [46], cockatiels in Japan [47], stone curlews in the United Arab Emirates [48], alpaca crias in the United States [49], chelonians in Australia [50], and rabbits in Poland [51]. The findings from our current study provide further information regarding cryptosporidiosis outbreaks among animal populations.

In conclusion, this is the first report of a cryptosporidiosis outbreak in Chinese dairy cattle. The C. parvum IIdA15G1 subtype was responsible for the reported outbreak as determined by genotyping and subtyping tools. Further studies are required to improve our understanding of the transmission and public health significance of Cryptosporidium species in China.

\section{Conclusions}

This is the first report of a cryptosporidiosis outbreak in Chinese dairy cattle. The C. parvum IIdA15G1 subtype was responsible for the reported outbreak as determined by genotyping and subtyping tools.

\section{Competing interests}

The authors declare that they have no competing interests.

\section{Authors' contributions}

RJW, LXZ conceived and designed the experiments; ZHC, JYH, and JQL performed the experiments; HYW, JFZ, ZJZ, and NNL analyzed the data; $Z H C, R J W$, and $L X Z$ wrote the manuscript. All the authors have read and approved the final version of the manuscript.

\section{Acknowledgments}

This study was supported in part by the State Key Program of the National Natural Science Foundation of China (31330079), the National Natural Science Foundation of China (U1204328, 31302079), the Specialized Research Fund for the Doctoral Program of Higher Education (20124105120003), and the Earmarked Fund for Modern Agro-industry Technology Research System (CARS-37).

Received: 5 November 2014 Accepted: 7 November 2014 Published online: 27 November 2014

\section{References}

1. Xiao L, Ryan U: Molecular epidemiology. In Cryptosporidium and Cryptosporidiosis. 2nd edition. Edited by Fayer R, Xiao L. Boca Raton: CRC Press and IWA Publishing: 2008:119-151.

2. Xiao L: Molecular epidemiology of cryptosporidiosis: An update. Exp Parasitol 2010, 124:80-89.

3. Ren X, Zhao J, Zhang L, Ning C, Jian F, Wang R, Lv C, Wang Q, Arrowood MJ, Xiao L: Cryptosporidium tyzzeri n. sp. (Apicomplexa: Cryptosporidiidae) in domestic mice (Mus musculus). Exp Parasitol 2012, 130:274-281.

4. Kvác $M$, Kestranova M, Pinkova M, Kvetonova D, Kalinova J, Wagnerova P, Kotkova M, Vitovec J, Ditrich O, McEvoy J, Stenger B, Sak B: Cryptosporidium scrofarum n. sp. (Apicomplexa: Cryptosporidiidae) in domestic pigs (Sus scrofa). Vet Parasitol 2013, 191:218-227.

5. Ryan U, Fayer R, Xiao L: Cryptosporidium species in humans and animals: current understanding and research needs. Parasitology 2014, 11:1-19.

6. Karanis $\mathrm{P}$, Kourenti $\mathrm{C}$, Smith $\mathrm{H}$ : Waterborne transmission of protozoan parasites: a worldwide review of outbreaks and lessons learnt. J Water Health 2007, 5:1-38.

7. Mac KWR, Hoxie NJ, Proctor ME, Gradus MS, Blair KA, Peterson DE, Kazmierczak JJ, Addiss DG, Fox KR, Rose JB, Davis JP: A massive outbreak in Milwaukee of Cryptosporidium infection transmitted through the public water supply. N Engl J Med 1994, 331:161-167.

8. Hopkins J, Hague H, Hudgin G, Ross L, Moore D: An outbreak of Cryptosporidium at a recreational water park in Niagara Region, Canada. J Environ Health 2013, 75:28-33.

9. Moon S, Kwak W, Lee S, Kim W, Oh J, Youn SK: Epidemiological characteristics of the first water-borne outbreak of cryptosporidiosis in Seoul, Korea. J Korean Med Sci 2013, 28:983-989.

10. Robertson $\sqcup$, Chalmers RM: Foodborne cryptosporidiosis: is there really more in Nordic countries? Trends Parasitol 2013, 29:3-9.

11. Widerström M, Schönning C, Lilja M, Lebbad M, Ljung T, Allestam G, Ferm M, Björkholm B, Hansen A, Hiltula J, Långmark J, Löfdahl M, Omberg M, Reuterwall C, Samuelsson E, Widgren K, Wallensten A, Lindh J: Large outbreak of Cryptosporidium hominis infection transmitted through the public water supply, Sweden. Emerg Infect Dis 2014, 20:581-589.

12. Trout JM, Santín M: Livestock. In Cryptosporidium and Cryptosporidiosis. 2nd edition. Boca Raton: CRC Press and IWA Publishing; 2008:451-483.

13. Wang R, Zhang L, Axén C, Bjorkman C, Jian F, Amer S, Liu A, Feng Y, Li G, Lv C, Zhao Z, Qi M, Dong H, Wang H, Sun Y, Ning C, Xiao L: Cryptosporidium 
parvum Ild family: clonal population and dispersal from Western Asia to other geographical regions. Sci Rep 2014, 4:4208.

14. Wang $R$, Wang $H$, Sun $Y$, Zhang L, Jian F, Qi M, Ning C, Xiao L: Characteristics of Cryptosporidium transmission in preweaned dairy cattle in henan, China. J Clin Microbio/ 2011, 49:1077-1082.

15. Wang R, Zhang L, Feng Y, Ning C, Jian F, Xiao L, Zhao J, Wang Y: Molecular characterization of a new genotype of Cryptosporidium from American minks (Mustela vison) in China. Vet Parasitol 2008, 154:162-166.

16. Wang R, Qiu S, Jian F, Zhang S, Shen Y, Zhang L, Ning C, Cao J, Qi M, Xiao L: Prevalence and molecular identification of Cryptosporidium spp. in pigs in Henan, China. Parasitol Res 2010, 107:1489-1494.

17. Wang R, Zhang X, Zhu H, Zhang L, Feng Y, Jian F, Ning C, Qi M, Zhou Y, Fu K, Wang Y, Sun Y, Wang Q, Xiao L: Genetic characterizations of Cryptosporidium spp. and Giardia duodenalis in humans in Henan, China. Exp Parasitol 2011, 127:42-45.

18. Lv C, Zhang L, Wang R, Jian F, Zhang S, Ning C, Wang H, Feng C, Wang X, Ren X, Qi M, Xiao L: Cryptosporidium spp. in wild, laboratory, and pet rodents in china: prevalence and molecular characterization. Appl Environ Microbiol 2009, 75:7692-7699.

19. Feng Y, Wang L, Duan L, Gomez-Puerta LA, Zhang L, Zhao X, Hu J, Zhang $N$, Xiao L: Extended outbreak of cryptosporidiosis in a pediatric hospital, China. Emerg Infect Dis 2012, 18:312-314.

20. Feng Y, Ortega Y, He G, Das P, Xu M, Zhang X, Fayer R, Gatei W, Cama V, Xiao L: Wide geographic distribution of Cryptosporidium bovis and the deer-like genotype in bovines. Vet Parasitol 2007, 144:1-9.

21. Sulaiman IM, Hira PR, Zhou L, Al-Ali FM, Al-Shelahi FA, Shweiki HM, labal J, Khalid N, Xiao L: Unique endemicity of cryptosporidiosis in children in Kuwait. J Clin Microbiol 2005, 43:2805-2809.

22. Blanchard PC: Diagnostics of dairy and beef cattle diarrhea. Vet Clin North Am Food Anim Pract 2012, 28:443-464.

23. Holland RE: Some infectious causes of diarrhea in young farm animals. Clin Microbiol Rev 1990, 3:345-375.

24. Chalmers RM, Smith R, Elwin K, Clifton-Hadley FA, Giles M: Epidemiology of anthroponotic and zoonotic human cryptosporidiosis in England and Wales, 2004-2006. Epidemiol Infect 2011, 139:700-712.

25. Liu AQ, Wang RJ, Li YH, Zhang LX, Shu J, Zhang WZ, Feng YY, Xiao LH, Ling $\mathrm{H}$ : Prevalence and distribution of Cryptosporidium spp. in dairy cattle in Heilongjiang Province, China. Parasitol Res 2009, 105:797-802.

26. Wang R, Ma G, Zhao J, Lu Q, Wang H, Zhang L, Jian F, Ning C, Xiao L: Cryptosporidium andersoni is the predominant species in post-weaned and adult dairy cattle in China. Parasitol Int 2011, 60:1-4.

27. Zhang W, Wang R, Yang F, Zhang L, Cao J, Zhang X, Ling H, Liu A, Shen Y: Distribution and genetic characterizations of Cryptosporidium spp. in pre-weaned dairy calves in Northeastern China's Heilongjiang Province. PLoS One 2013, 8:e54857.

28. Zhao GH, Ren WX, Gao M, Bian QQ, Hu B, Cong MM, Lin Q, Wang RJ, Qi M, Qi MZ, Zhu XQ, Zhang LX: Genotyping Cryptosporidium andersoni in cattle in Shaanxi province, Northwestern China. PLoS One 2013, 8:e60112.

29. Santín M, Trout JM, Fayer R: A longitudinal study of cryptosporidiosis in dairy cattle from birth to 2 years of age. Vet Parasitol 2008, 155:15-23.

30. Gait R, Soutar RH, Hanson M, Fraser C, Chalmers R: Outbreak of cryptosporidiosis among veterinary students. Vet Rec 2008, 162:843-845.

31. Pönka A, Kotilainen $H$, Rimhanen-Finne $R$, Hokkanen $P$, Hänninen ML, Kaarna A, Meri T, Kuusi M: A foodborne outbreak due to Cryptosporidium parvum in Helsinki, November 2008. Euro Surveill 2009, 14:1-3.

32. Grinberg A, Pomroy WE, Squires RA, Scuffham A, Pita A, Kwan E: Retrospective cohort study of an outbreak of cryptosporidiosis caused by a rare Cryptosporidium parvum subgenotype. Epidemiol Infect 2011, 139:1542-15450

33. Lange $\mathrm{H}$, Johansen $\mathrm{OH}$, Vold $\mathrm{L}$, Robertson $\mathrm{U}$, Anthonisen IL, Nygard K: Second outbreak of infection with a rare Cryptosporidium parvum genotype in schoolchildren associated with contact with lambs/goat kids at a holiday farm in Norway. Epidemiol Infect 2013, 5:1-9.

34. Quílez J, Torres E, Chalmers RM, Hadfield SJ, Del Cacho E, Sánchez-Acedo C: Cryptosporidium genotypes and subtypes in lambs and goat kids in Spain. Appl Environ Microbiol 2008, 74:6026-6031.

35. Quilez J, Torres E, Chalmers RM, Robinson G, Del Cacho E, Sanchez-Acedo C: Cryptosporidium species and subtype analysis from dairy calves in Spain. Parasitology 2008, 135:1613-1620.
36. Muhid A, Robertson I, Ng J, Ryan U: Prevalence of and management factors contributing to Cryptosporidium sp. infection in pre-weaned and post-weaned calves in Johor, Malaysia. Exp Parasitol 2011, 127:534-538.

37. Nazemalhosseini-Mojarad E, Haghighi A, Taghipour N, Keshavarz A, Mohebi SR, Zali MR, Xiao L: Subtype analysis of Cryptosporidium parvum and Cryptosporidium hominis isolates from humans and cattle in Iran. Vet Parasitol 2011, 179:250-252.

38. Wielinga PR, de Vries A, van der Goot TH, Mank T, Mars MH, Kortbeek LM, van der Giessen JW: Molecular epidemiology of Cryptosporidium in humans and cattle in The Netherlands. Int J Parasitol 2008, 38:809-817.

39. Ajjampur SS, Liakath FB, Kannan A, Rajendran P, Sarkar R, Moses PD, Simon A, Agarwal I, Mathew A, O'Connor R, Ward H, Kang G: Multisite study of cryptosporidiosis in children with diarrhea in India. J Clin Microbiol 2010, 48:2075-2081

40. $\mathrm{Ng}$ J, MacKenzie B, Ryan U: Longitudinal multi-locus molecular characterisation of sporadic Australian human clinical cases of cryptosporidiosis from 2005 to 2008. Exp Parasitol 2010, 125:348-356.

41. Iqbal A, Lim YA, Surin J, Sim BL: High diversity of Cryptosporidium subgenotypes identified in Malaysian HIV/AIDS individuals targeting gp60 gene. PLoS One 2012, 7:e31139.

42. Adamu H, Petros B, Zhang G, Kassa H, Amer S, Ye J, Feng Y, Xiao L: Distribution and clinical manifestations of Cryptosporidium species and subtypes in HIV/AIDS patients in Ethiopia. PLoS Negl Trop Dis 2014, 8:e2831.

43. Yang R, Jacobson C, Gardner G, Carmichael I, Campbell AJ, Ng-Hublin J, Ryan U: Longitudinal prevalence, oocyst shedding and molecular characterisation of Cryptosporidium species in sheep across four states in Australia. Vet Parasitol 2014, 200:50-58.

44. Vieira LS, Silva MB, Tolentino AC, Lima JD, Silva AC: Outbreak of cryptosporidiosis in dairy goats in Brazil. Vet Rec 1997, 140:427-428.

45. Johnson EH, Muirhead DE, Windsor JJ, King GJ, Al-Busaidy R, Cornelius R: Atypical outbreak of caprine cryptosporidiosis in the Sultanate of Oman. Vet Rec 1999, 145:521-524.

46. Grinberg A, Oliver L, Learmonth JJ, Leyland M, Roe W, Pomroy WE: Identification of Cryptosporidium parvum 'cattle' genotype from a severe outbreak of neonatal foal diarrhoea. Vet Rec 2003, 153:628-631.

47. Kwon YK, Wee SH, Kook JH, Lee CG: Outbreak of enteric cryptosporidiosis in cockatiels (Nymphicus hollandicus). Vet Rec 2005, 156:210-211.

48. Zylan K, Bailey T, Smith HV, Silvanose C, Kinne J, Schuster RK, Hyland K. An outbreak of cryptosporidiosis in a collection of Stone curlews (Burhinus oedicnemus) in Dubai. Avian Pathol 2008, 37:521-526.

49. Starkey SR, Johnson AL, Ziegler PE, Mohammed HO: An outbreak of cryptosporidiosis among alpaca crias and their human caregivers. J Am Vet Med Assoc 2007, 231:1562-1567.

50. Richter B, Rasim R, Vrhovec MG, Nedorost N, Pantchev N: Cryptosporidiosis outbreak in captive chelonians (Testudo hermanni) with identification of two Cryptosporidium genotypes. J Vet Diagn Invest 2012, 24:591-595.

51. Kaupke A, Kwit E, Chalmers RM, Michalski MM, Rzeżutka A: An outbreak of massive mortality among farm rabbits associated with Cryptosporidium infection. Res Vet Sci 2014, 97:85-87.

doi:10.1186/s13071-014-0529-z

Cite this article as: Cui et al:: Cryptosporidiosis caused by Cryptosporidium parvum subtype IIdA15G1 at a dairy farm in Northwestern China. Parasites \& Vectors 2014 7:529.

\section{Submit your next manuscript to BioMed Central and take full advantage of:}

- Convenient online submission

- Thorough peer review

- No space constraints or color figure charges

- Immediate publication on acceptance

- Inclusion in PubMed, CAS, Scopus and Google Scholar

- Research which is freely available for redistribution 